\title{
KAJIAN KONDISI INFRASTRUKTUR JALAN LINGKUNGAN DI KAWASAN KELURAHAN 3-4 ULU PALEMBANG
}

\author{
AHMAD HIDAYAT ${ }^{1)}$, SAMARA GUMAY PUTRA ${ }^{2)}$ \\ ${ }^{1)}$ Dosen Teknik Sipil Universitas Tamansiswa Palembang \\ ${ }^{2)}$ Mahasiswa Teknik Sipil Universitas Tamansiswa Palembang \\ Jalan Tamansiswa No. 261.Palembang kode pos 30126 \\ ${ }^{1)}$ E-mail : A.Hidayat@unitaspalembang.ac.id \\ ${ }^{2)}$ E-mail : samaragumay.putra@yahoo.com
}

\begin{abstract}
ABSTRAK
Salah satu infrastruktur yang terpenting pada suatu lokasi adalah memiliki jalan yang memadai. Kondisi kawasan padat penduduk merupakan permasalahan yang sering timbul di perkotaan. Salah satu permasalahan yang sering timbul adalah masalah infrastruktur jalan. Banyaknya penduduk yang tinggal di kawasan tersebut dan terbatasnya lahan menyebabkan sangat perlunya bantuan penanganan masalah infrastruktur jalan lingkungan di kawasan tersebut. Untuk perencanaan pembangunan infrastruktur jalan yang terpadu tentu memerlukan survey akan kebutuhan jalan lingkungan tersebut. Berdasarkan hasil survey dan observasi di lapangan, didapatkan bahwa infrastruktur jalan yang sudah ada membutuhkan peningkatan, perbaikan dan pembuatan yang baru. Salah satunya adalah pembuatan jalan titian yang sangat membutuhkan penanganan khusus karena sudah banyak jalan titian yang patah akibat tidak dirawat. Lokasi 3-4 Ulu yang sebagian besar terletak di bantara sungai Musi tentu sangat mengalami pasang surut air sungai Musi. Oleh karena itu penanganan terhadap kawasan ini sangat membutuhkan upaya ekstra dari pemerintah. Untuk itulah penelitian ini dibuat, salah satunya adalah untuk membantu pihak kelurahan dalam penanganan masalah infrastruktur jalan.
\end{abstract}

Kata Kunci : Kawasan padat penduduk, infrastruktur jalan, terpadu, terintegrasi.

\section{PENDAhULUAN}

Infrastruktur jalan merupakan fasilitas utama yang dapat mengembangkan suatu kawasan. Jalan yang terintegrasi di suatu wilayah juga merupakan hal yang sangat penting. Apalagi untuk kawasan perkotaan yang sangat aktif, tentulah sangat dibutuhkan akses yang lengkap guna menunjang kelancaran dan perkembangan wilayah tersebut.

Disadari bahwa pengelolaan suatu wilayah perkotaan sangat rumit dan kompleks, serta melibatkan banyak sektor, bidang dan stakeholder, namun secara umum bidang pengelolaan perkotaan dapat dibagi menjadi 2 bidang yaitu, bidang fisik dan bidang non fisik. Untuk pembangunan infrastruktur jalan sendiri menjadi salah satu pembangunan bidang fisik.

Kelurahan 3-4 Ulu Kecamatan SU-1 merupakan salah satu kawasan berkembang yang terletak di tengah kota. Menurut SK Walikota Palembang Tahun 2016, Kelurahan 3-4 Ulu ini merupakan kelurahan yang termasuk kawasan kumuh. Salah satu penilaian kekumuhannya adalah karena infrastruktur jalan lingkungan yang sangat kurang di lokasi ini. Jalan lingkungan dalam hal ini dapat berupa jalan rabat atau cor beton, dan juga jalan titian yang digunakan apabila di bawahnya terdapat anak sungai.

Pentingnya bahasan mengenai perencanaan infrastruktur jalan lingkungan ini membuat penulis tertarik untuk meneliti. Selain dengan memperhatikan kondisi eksisting, juga akan dibahas dan diuraikan rencana anggaran biaya yang diperlukan untuk penyelesaian permasalahan infrastruktur jalan ini agar kawasan 3-4 Ulu ini dapat menjadi kawasan yang layak dan perlahan - lahan bebas dari kekumuhan. Di samping itu lokasi di kelurahan 3-4 Ulu merupakan kawasan yang berada di lokasi padat penduduk dengan keanekaragaman budaya. 


\section{A. Tujuan Penelitian}

Berdasarkan pendahuluan yang telah diuraikan maka tujuan yang ingin dicapai adalah:

a) Memahami kondisi eksisting infrastruktur jalan lingkungan di Kelurahan 3-4 Ulu.

b) Merencanakan pembangunan infrastruktur jalan lingkungan yang teritegrasi di kawasan 3-4 Ulu.

c) Mengetahui total biaya rencana pembangunan infrastruktur jalan lingkungan di Kelurahan 34 Ulu.

\section{B. Kajian Literatur}

1. Pengertian Kota

Definisi klasik kota menurut Rapoport dalam Zahnd (1999; 4) adalah suatu permukiman yang relatif besar, padat dan permanen, terdiri dari kelompok individu-individu yang heterogen dari segi sosial. Dari definisi di atas, perkmukiman/kota digambarkan sebagai objek yang mempunyai unsur sosial yang mempengaruhi kegiatan yang pada pembangunan berkelanjutan (sustainable).

Kota sebagai tempat terpusatnya kegiatan masyarakat akan terus berkembang dengan semakin kompleksnya kegiatan-kegiatan dalam kota, kota tidak lagi mempunyai fungsi tunggal (single use) dalam-pemenuhan kebutuhan masyarakatnya namun memiliki kecenderungan multi fungsi (mixed use) dengan fungsi kegiatan yang berorientasi pada kepentingan pasar dan kepentingan publik. Sehinggakota dapat diartikan sebagai suatu lokasi dengan konsentrasi penduduk / permukiman, kegiatan sosial ekonomi yang heterogen dan intensif (bukan ekstraktif sepertinya pertanian), pemusatan, koleksi dan distribusi pelayanan jasa pemerintahan sosial ekonomi yang ditetapkan secara administratif. Jika kota adalah suatu wilayah yang ditetapkan secara administratif, perkotaan tidak terbatas pada penetapan administratif, namun berdasarkan ciri-ciri perkotaan yang dimiliki oleh suatu wilayah. Dalam UU Penataan ruang No.26 tahun 2007, kawasan perkotaan adalah wilayah yang mempunyai kegiatan utama bukan pertanian dengan susunan fungsi kawasan sebagai tempat permukiman perkotaan, pemusatan dan distribusi pelayanan pemerintahan, pelayanan sosial dan kegiatan ekonomi.
2. Kriteria kawasan perkotaan meliputi :

Adapun kriteria kawasan perkotaan

1. Memiliki karakteristik kegiatan utama budidaya bukan pertanian atau mata pencaharian penduduknya terutama di bidang industri, perdagangan dan jasa;

2. Memiliki karakteristik sebagai pemusatan dan distribusi pelayanan barang dan jasa didukung prasarana dan sarana termasuk pergantian modal transportasi dengan pelayanan skala kabupaten atau beberapa kecamatan.

Berdasarkan UU No.32 Tahun 2004 tentang Pemerintah Daerah Kawasan Perkotaan dapat berbentuk :

- Kota sebagai daerah otonom; adalah kota yang dikelola oleh pemerintah kota;

- Kotayang menjadi bagian daerah kabupaten yang memiliki ciri perkotaan; adalah kota yang dikelola oleh daerah atau lembaga pengelola yang dibentuk dan bertanggungjawab kepada pemerintah kabupaten.

- Kota yang menjadi bagian dari dua atau lebih daerah yang berbatasan langsung dan memiliki ciri perkotaan; dalam hal penataan ruang dan penyediaan fasilitas pelayanan umum tertentu dikelola bersama oleh daerah terkait.

Klasifikasi Kawasan Perkotaan berdasarkan jumlah penduduk, dibagi menjadi :

- Kawasan Perkotaan Kecil, yaitu Kawasan Perkotaan dengan jumlah penduduk yang dilayani sebesar 10.000 hingga 100.000 jiwa;

- Kawasan Perkotaan Sedang, yaitu Kawasan Perkotaan dengan jumlah penduduk yang dilayani sebesar 100.001 hingga 500.000 jiwa;

- Kawasan Perkotaan Besar, yaitu Kawasan Perkotaan dengan jumlah penduduk yang dilayani lebih besar dari 500.000 jiwa;

- Kawasan Perkotaan Metropolitan, yaitu Kawasan Perkotaan dengan jumlah penduduk yang dilayani lebih besar dari 1.000.000 jiwa.

\section{Pengelompokan Jalan}

Pengelompokan jalan atau hierarki jalan adalah pengelompokan jalan berdasarkan fungsi jalan, berdasarkan administrasi pemerintahan dan berdasarkan muatan sumbu yang menyangkut dimensi dan berat kendaraan. Penentuan klasifikasi jalan terkait dengan besarnya volume 
lalu lintas yang menggunakan jalan tersebut, besarnya kapasitas jalan, keekonomian dari jalan tersebut serta pembiayaan pembangunan dan perawatan jalan. Di Indonesia pengelompokan jalan diatur di UU No. 22 Tahun 2009.

a. Klasifikasi berdasarkan administrasi pemerintahan

Pengelompokan jalan dimaksudkan untuk mewujudkan kepastian hukum penyelenggaraan jalan sesuai dengan kewenangan Pemerintah dan pemerintah daerah. Jalan umum menurut statusnya dikelompokkan ke dalam jalan nasional, jalan provinsi, jalan kabupaten, jalan kota, dan jalan desa.

b. Klasifikasi berdasarkan beban muatan sumbu

Untuk keperluan pengaturan penggunaan dan pemenuhan kebutuhan angkutan, jalan dibagi dalam beberapa kelas yang didasarkan pada kebutuhan transportasi, pemilihan moda secara tepat dengan mempertimbangkan keunggulan karakteristik masing-masing moda, perkembangan teknologi kendaraan bermotor, muatan sumbu terberat kendaraan bermotor serta konstruksi jalan.

Pengelompokkan jalan menurut muatan sumbu yang disebut juga kelas jalan, terdiri dari : jalan arteri ( Kelas I dan II ), jalan kolektor ( Kelas III A dan III B), jalan lokal dan lingkungan ( Kelas III C).

\section{Konstruksi Jalan Lingkungan}

Dalam penelitian ini difokuskan pada jalan lingkungan, maka tinjauan pustakanya pun terfokus pada konstruksi jalan lingkungan. Ada beberapa konstruksi jalan lingkungan, yaitu :
a. Jalan Tanah
b. Jalan Kerikil
c. Jalan Aspal Tipis
d. Jalan Telford
e. Jalan Makadam
f. Jalan Paving Blok

5. Jenis Pengerasan Jalan Lingkungan yang Paling Populer

Jalan lingkungan didefinisikan sebagai jalan umum yang melayani angkutan lingkungan terutama untuk angkutan jarak dekat. Kecepatan rata-rata kendaraan pun lebih rendah dan ukuran kendaraan lebih kecil. Biasanya berada pada kawasan rumah dengan desain tertentu dari developer. Meski demikian status kepemilikan adalah milik negara sebagai fasilitas umum.

Pembangunan dan pengerasan jalan lingkungan hingga perawatannnya bisa dilakukan oleh siapa saja, baik warga sekitar maupun pemerintah setempat. Sehingga menjadi tanggung jawab semua pihak yang berada di daerah tersebut. Akibat lain kita sering menemukan ada pungutan lingkungan untuk pembangunan dan perawatan jalan. Meski sebenarnya pemerintah daerah juga sudah menganggarkan untuk kebutuhan ini. Pada bagian struktur, perkerasan jalan lingkungan dibagi menjadi beberapa lapis yaitu lapisan tanah dasar (sub grade), pondasi dasar (subbase course), pondasi atas (base course) dan lapisan permukaan/penutup (surface course). Ditinjau dari teknik yang digunakan, pengerasan jalan lingkungan bisa dilakukan dengan tiga jenis cara yang berbeda yaitu sebagai berikut:

a. Perkerasan Jalan Lentur Menggunakan Aspal (Flexibel Pavement)

Teknik ini dilakukan dengan cara mengikat aspal yang diberikan campuran aspal panas dan hot mix. Bahan dasar aspal hingga saat ini masih menggunakan import dari luar negari yaitu aspal shell, ESSO 2000 dan yang lainnya. Komposisi dasar $60 \%$ berupa aspal dari total semua hotmix.

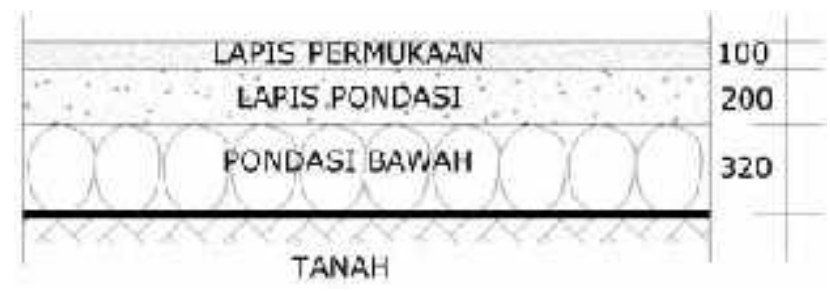

Gambar 1 Perkerasan lentur

Jalan aspal saat ini masih menjadi primadona dan digunakan pada mayoritas jalan di Indonesia. Karakteristiknya serta biaya konstruksi sangat berbdeda dengan jalan tanah. Kelebihan jalan aspal adalah sebagai berikut:

a. Lebih mulus, halus serta tidak bergelombang alhasil berkendara lebih nyaman

b. Warnanya mempengaruhi psikologi pengguna jalan menjadi lebih nyaman dan teduh

c. Biaya pembangunan lebih murah dibandingkan konstruksi jalan beton 
d. Perawatan lebih mudah yakni mengganti area rusak saja dengan baru

Namun juga memiliki kekurangan yaitu tidak tahan terhadap genangan air sehingga drainase harus berfungsi optimal saat hujan atau banjir. Apabila struktur tanah buruk akan terlihat jelas dan harus diperbaiki struktur tanahnya terlebih dahulu sebelum memperbaiki konstruksi jalan.

b. Perkerasan Jalan Kaku Menggunakan Beton (Rigid Pavement)

Perkerasan kaku menggunakan bahan beton semen ini menggunakan plat (slab) beton semen sebagai pondasi dan lapisan lapisan pondasi bawah atau bisa juga berada di atas tanah dasar. Konstruksi model ini, plat beton disebut sebagai lapisan pondasi karena kadangkala memungkinkan ditambah lapisan aspal beton di atasnya untuk bagian permukaan.

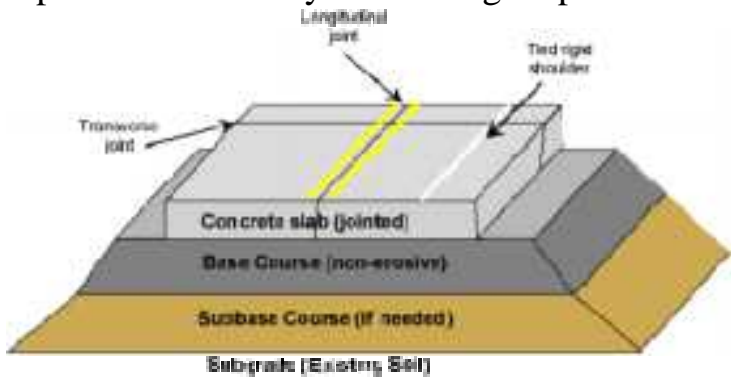

Gambar 2. Perkerasan kaku

Perkerasan beton kaku ini mempunyai modulus elastisitas tinggi sehingga akan mendistribusikan beban pada bidang tanah dasar yang cukup luas sehingga bagian terbesar dari kapasitas struktur ini didapat dari plat beton. Cara ini beda dengan perkerasan lebtur yang kekuatan perkerasan dari tebal pondasi lapis bagian bawah, lapis pondasi serta lapis permukaan.

Pada pengerasan jalan lingkungan kaku dengan beton ini harus mengetahui kapasitas struktur yang akan menahan beban agar perencanaan beban tebal beton bisa dilakukan untuk kekuatan yang optimal. Sedangkan daya dukung dan kapasitas struktur tanah hanya berpengaruh kecil terhadap awet dan tidaknya jalan beton.

Lapisan jalan beton memiliki kelebihan yaitu menahan beban kendaraan berat, tahan genangan air saat hujan, biaya perawatan lebih murah dari pada aspal, bisa digunakan pada struktur tanah buruk, material lebih mudah diperoleh. Sedangkan kekurangannya yaitu kualitas sangat dipengaruhi oleh proses pelaksanaan yaitu:

- Pengeringan yang terlalu cepat bisa mengakibatkan keretakan, sehingga ditambahkan dengan zat kimia pada campuran beton dan ditutup dengan kain basah.

- Pada jalan raya dengan kapasitas berat terlalu tinggi, pembuatan jalan beton lebih mahal dibandingkan aspal, namun lebih murah saat perawatan.

- Kehalusan serta gelombang sangat ditentukan proses pengecoran dan harus diawasi dengan ketat.

- Perbaikan jalan harus dilakukan dengan meninggikan elevasi tanah, sehingga berpengaruh terhadap ketinggian jalan.

- Warna beton terlihat lebih gersang dan keras dan pengendara kurang nyaman.

\section{c. Perkerasan Jalan Paving Blok (Block Pavement)}

Perkerasan jalan dengan paving block dilakukan dengan campuran pasir dan semen yang telah ditambah campuran lain atau tidak. Paving block terkunci telah distandarisasikan melalui SII.0819-88 yaitu takaran komposisi bahan bangunan yang terbuat dari campuran semen paortland atau bahan perekat hidrolis lain, air serta agregat lain tanpa atau dengan bahan lain.

Menurut SK SNI T-04-1990-F, paving block merupakan segmen-segmen kecil yang dibuat dari beton berbentuk segi empat atau segi banyak yang dipasang sehingga mengunci. (Dudung Kumara, 1992; Akmaluddin dkk. 1998).

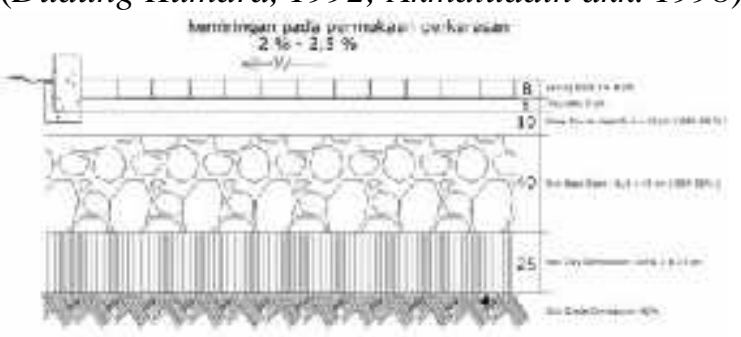

Gambar 3. Paving Block

$\begin{array}{ccc}\text { Keunggulan paving block untuk } \\ \text { pengerasan jalan } & \text { lingkungan yaitu }\end{array}$ mempermudah melakukan pemasangan tanpa alat berat, bisa dibongkar, elastis, dinamik, kejut dan tahan tumpahan bahan pelumas atau pemanasan mesin kendaraan. Sedangkan kelemahannya adalah bila pondasi tidak kuat 
akan mengakibatkan pengendara kurang nyaman pada kecepatan tinggi. Sehingga struktur ini sering dijadikan alasan agar kendaraan bisa melaju lambat di area pemukiman.

\section{METODE PENELITIAN}

\section{A. Langkah-Langkah Penelitian}

Secara garis besar, prosedur kerja penelitian mempunyai tahapan- tahapan, yaitu tahap perencanaan penelitian, tahap pelaksanaan, dan tahapan pembuatan laporan. Namun untuk lebih detainya kegiatan penelitian yang dilaksanakan oleh peneliti terdiri atas :

a) Memilih dan mengidentifikasi permasalahan yang akan diteliti.

b) Melakukan studi pendahuluan, yang bertujuan untuk mencari informasi yang diperlukan. Pada studi pendahuluan ini juga dilakukan observasi tempat yang menjadi objek penelitian.

c) Menentukan metode penelitian dari objek penelitian, sumber data, dan metode analisis;

d) Pengumpulan data baik data primer maupun data sekunder. Data primer yang dibutuhkan meliputi : dokumentasi, survey (observasi) ke lokasi kelurahan 3-4 Ulu, dan wawancara ke stake holder kelurahan dan masyarakat. Data sekunder berupa data-data publik (arsip, kepustakaan, laporan, jurnal, SNI, UU RI) dan referensi mengenai infrastruktur jalan lingkungan. Data sekunder terdiri dari data-data mengenai peraturan mengenai jalan lingkungan yang berlaku.

e) Analisis dan pembahasan.

h) Penarikan Kesimpulan

\section{B. Lokasi dan Waktu Penelitian}

Lokasi Penelitian adalah di Kelurahan 3-4 Ulu Kecamatan SU-I Palembang Propinsi Sumatera Selatan. Lama pelaksanaan penelitian adalah selama 3 bulan mulai dari bulan November 2018 - Januari 2019.

\section{Metode Pengumpulan Data}

Teknik pengambilan data dilakukan dengan melakukan survey dan dokumentasi di lapangan. Pemetaan yang sudah ada diolah dengan menggunakan program Argis dan dan dibuat peta tematik mengenai kondisi eksisting infrastruktur jalan lingkungan. Disamping itu juga dilakukan wawancara dengan stake holder di kelurahan 3-4 Ulu untuk penanganan permasalahan infrastruktur.

\section{Diagram Alir Pelaksanaan}

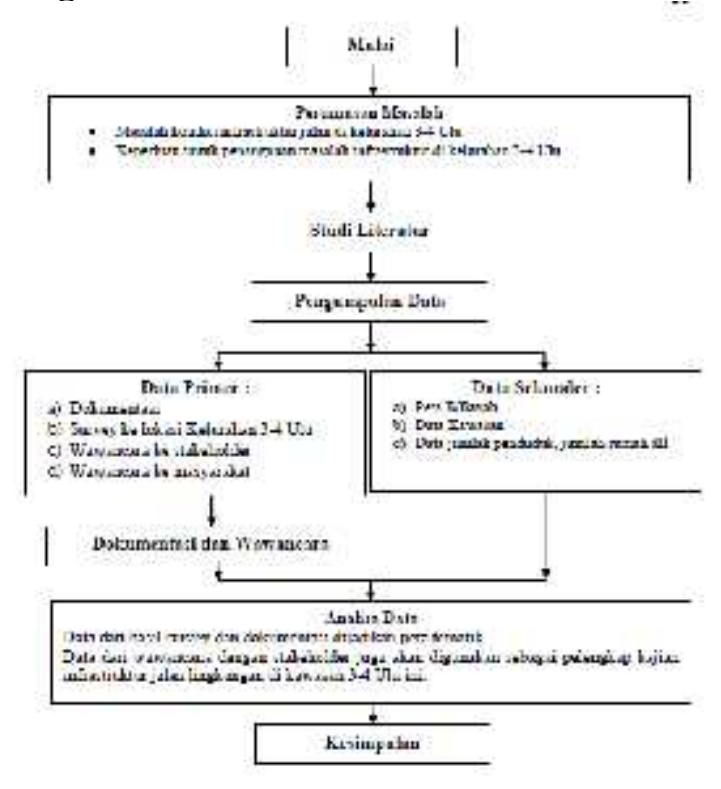

Gambar 4. Diagram Alir Penelitian

\section{HASIL PENELITIAN}

\section{A. Kondisi Umum Kawasan Kelurahan \\ 3-4 Ulu}

Kelurahan 3-4 Ulu adalah salah satu kelurahan yang terletak di Kecamatan Seberang Ulu I - Kota Palembang. Kelurahan 3-4 Ulu merupakan desa dengan luas wilayah 1.359.200 $\mathrm{m} 2=135,92 \mathrm{Ha}$, yang di kepalai oleh seorang Lurah dan dibantu oleh 13 Ketua RW, serta 55 Ketua RT.

Kelurahan 3-4 Ulu memiliki batas wilayah sebagai berikut :

Sebelah Utara : Kelurahan 28 Ilir / Sungai Musi

Sebelah Timur : Kelurahan 5 Ulu

Sebelah Selatan : Kelurahan 15 Ulu

Sebelah Barat : Kel. 2 Ulu dan Kel. Tuan Kentang 


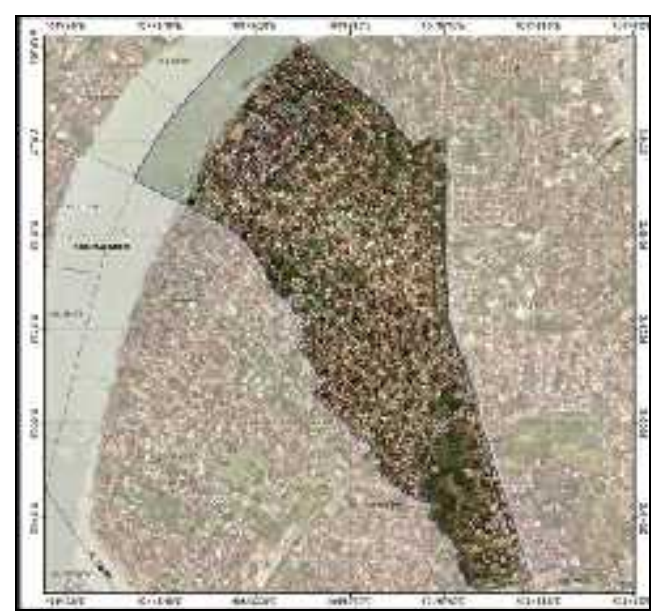

Gambar 5. Peta Wilayah Kelurahan 3-4 Ulu

Jumlah penduduk Kelurahan 3-4 Ulu sebanyak 16.334 Jiwa yang terdiri dari 8.233 penduduk laki-laki dan 8.101 penduduk perempuan, dengan kepadatan penduduk sebesar $104 \mathrm{Jiwa} / \mathrm{Ha}$.

Jumlah Kepala Keluarga yang ada di Kelurahan 3-4 Ulu sebanyak 3.116 KK dan Jumlah Kepala Rumah Tangga sebanyak 4.127 KRT dengan dengan Kepala Rumah Tangga MBR (masyarakat berpenghasilan rendah) sebanyak 2.342 KRT dan Kepala Rumah Tangga Non MBR sebanyak 774 KRT.

Kawasan kelurahan dengan luas lahan 135,92 Ha dibagi kedalam 55 RT. Penggunaan lahannya yang ada saat ini sebagian besar digunakan untuk fungsi permukiman dengan luas sekitar $=113.20 \mathrm{Ha}$ atau 83,28 \%, sedangkan $22,92 \mathrm{Ha}$ atau $16,72 \%$ nya merupakan lahan kosong, jalan lingkungan, sungai, kawasan perdagangan/jasa,fasilitas umum dan fasilitas sosial.

Kondisi bangunan di kawasan permukiman merupakan salah satu kriteria atau indikator apakah kawasan permukiman tersebut dalam kategori kumuh atau tidak. Jumlah permukiman di Kelurahan 3-4 Ulu hasil Baseline data tahun 2015 sebanyak 113,23 ha, dengan jumlah bangunan hunian sebanyak 3.316 unit. dengan jumlah tingkat kepadatan bangunan 27,52 unit/Ha.

\section{B. Infrastruktur Eksisting Jalan Lingkungan di Kawasan Kelurahan 3-4 Ulu}

Jalan lingkungan yang baik, harus memberikan rasa yang aman dan nyaman bagi pergerakan pejalan kaki dan kendaraan bermotor. Selain itu, harus didukung pula oleh ketersediaan prasarana pendukung jalan seperti perkerasan jalan, trotoar, drainase, lansekap, rambu lalu lintas, parkir dan lain-lain. Analisis kondisi umum jalan yang berada di wilayah kelurahan 34 Ulu adalah sebagai berikut :

- Jalan KH. Wahid Hasim merupakan jalan utama yang menghubungkan antara Kelurahan (disekitar kecamatan Seberang Ulu I) dan juga merupakan akses jalan kota menuju Kec. Kertapati (Stasiun Kereta Api) dan menuju pusat kota Palembang, yang membentang sepanjang $\pm 0,465 \mathrm{~km} \mathrm{di}$ wilayah Kelurahan 3-4 Ulu dengan perkerasan Aspal dan lebar perkerasan $\pm 8 \mathrm{~m}$ ( 2 jalur dengan di batasi median $+0,60 \mathrm{~m}$ ), Kondisi jalan di lengkapi dengan bahu jalan \pm $1 \mathrm{~m}$ dan drainase kiri kanan dengan lebar 70 $\mathrm{cm}$ dan dalam sekitar +1 meter.

- Jalan KH. Wahid Hasim dilewati Rute trayektrayek angkutan umum, yaitu rute Terminal Karya Jaya - Jakabaring, Terminal Karya Jaya - Jl. Sriwijaya Raya - Jl. Lingkar Selatan - Jl. H. Bastari Jl. KH. Wahid Hasyim - Jl. KI Marogan - Jl. Sriwijaya Raya - Terminal Karya jaya

- Dari jalan utama menuju ke dalam (kawasan permukiman) terdapat jalan KH. A. Azhari dan Jl. H. Faqih Usman dengan perkerasan beton hotmix dengan lebar $+7 \mathrm{~m}$, dimana jalan ini bisa menghubungkan ke kelurahan 2 ulu dan kel. 5 ulu, selain itu merupakan akses jalan menuju kantor lurah maupun kantor polisi (Mapolsek SU.I) . Jalan KH. Moh. Asyik merupakan jalan lingkungan permukiman yang menghubungkan antara kawasan permukiman dengan sistem jaringan utama jalan raya dengan sebagian sisi jalan belum ada saluran draiansenya.

- Jalan lokal dan jalan lingkungan hampir tersebar diseluruh kawasan permukiman dengan dimensi jalan lebar sekitar 0,80 - 2 meter, yang sebagian besar belum ada saluran draiansenya serta kondisi sudah banyak yang rusak (bahkan masih ada yang belum diperkeras atau struktur kayu). 


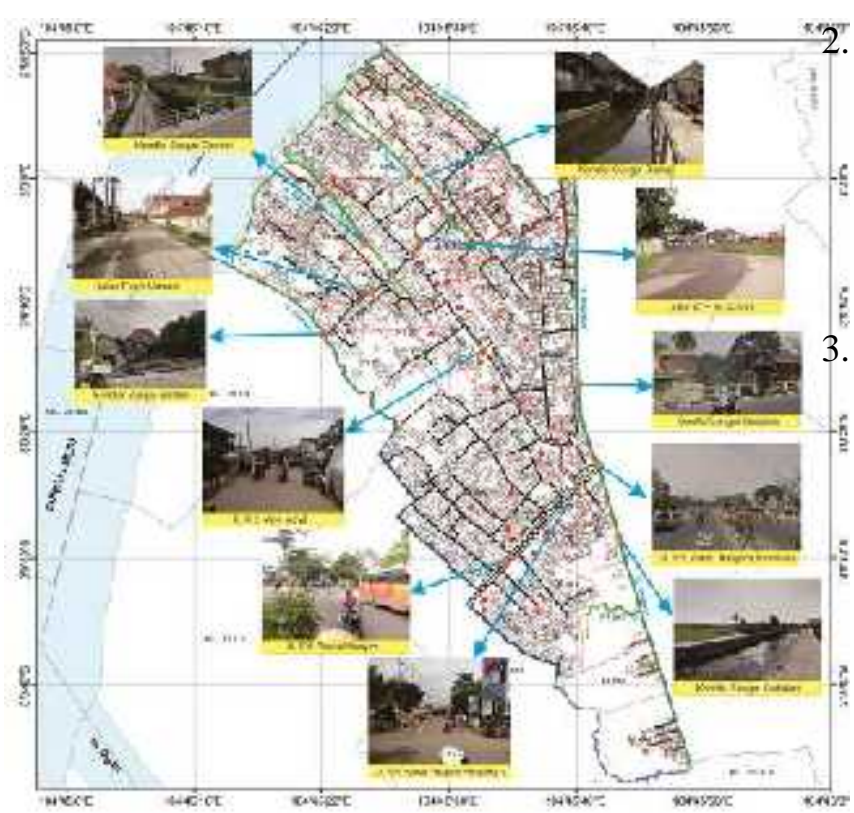

Gambar 6. Peta Eksisiting Fasilitas Umum (Jalan \& Sungai/ Drainase)

Kriteria jalan lingkungan yang diharapkan adalah sebagai berikut :

1. Kondisi permukaan jalan yang tidak dapat dilalui kendaraan dengan aman dan nyaman

2. lebar jalan yang tidak memadai

3. kelengkapan jalan yang tidak memadai

Namun kondisi eksisting di lapangan sangat jauh dari ketiga kriteria tersebut, yang dapat dilihat dari dokumentasi yang diambil di lapangan.

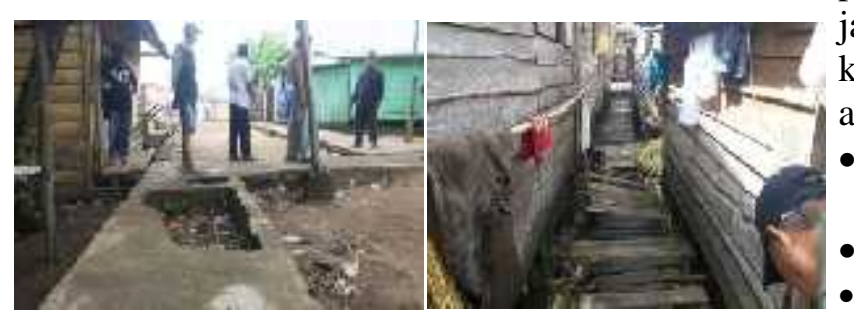

. Pada jalan lingkungan seringkali terendam aliran banjir. Terendamnya jalan tersebut sebagai akibat pendangkalan saluran drainase akibat aliran lumpur dan sampah sehingga seringkali meluap ke badan jalan (terutama terjadi pada waktu hujan dan pasang sungai secara bersamaan

3. Sama halnya dengan jaringan jalan utama masalah banjir merupakan penyebab menurunnya kualitas pelayanan jaringan jalan lokal atau lingkunganyang melayani permukiman warga. Selain belum adanya saluran drainase juga tidak mengalirnya saluran drainase akibat pendangkalan oleh lumpur dan sampah, penurunan kapasitas saluran drainase juga disebabkan oleh pemanfaatan saluran drainase oleh penduduk setempat. Lemahnya pengawasan dan kesadaran masyarakat menyebabkan jalan dan drainase merupakan sesuatu yang digunakan untuk mengalirkan air, sampah dan buangan lainnya sehingga menyebabkan tidak berfungsinya jaringan jalan yang tersedia.

4. Permasalahan mengenai keterbatasan jaringan jalan lingkungan tersebut juga dirasakan diwilayah perencanaan. Beberapa jalan yang terendam air kondisinya sudah rusak berat, selain itu rata-rata lebar jalan yang ada $<1,50$ (dimana sebagian besar masyarakat belum mau menghibahkan sedikit lahannya untuk pelebaran jalan menjadi $1,50 \mathrm{~m}$.

Jaringan jalan lingkungan di kawasan prioritas pada umumnya telah terkoneksi ke jaringan jalan skunder (jalan di kawasan kelurahan/kecamatan), yang menjadi persoalan adalah:

- Jaringan jalan lingkungan permukiman memiliki lebar $<1,5 \mathrm{~m}$

- Tidak dilengkapi dengan drainase

- Masih ada jalan tanah dan kayu

Gambar 7. Kondisi eksisting jalan lingkungan di kelurahan 3-4 Ulu

Permasalahan infrastruktur jaringan jalan yang seringkali ditemui di kelurahan 3-4 Ulu adalah sebagai berikut:

1. Tingginya pergerakan kendaraan umum dan aktivitas sepanjang jalan yang dibatasi oleh kapasitas jalan yang tersedia sehingga seringkali terjadi kemacetan di sepanjang jalan KH. Wahid Hasyim. Hal tersebut belum lagi diperparah apabila sedang dilakukan perbaikan konstruksi jalan maupun drainase. 


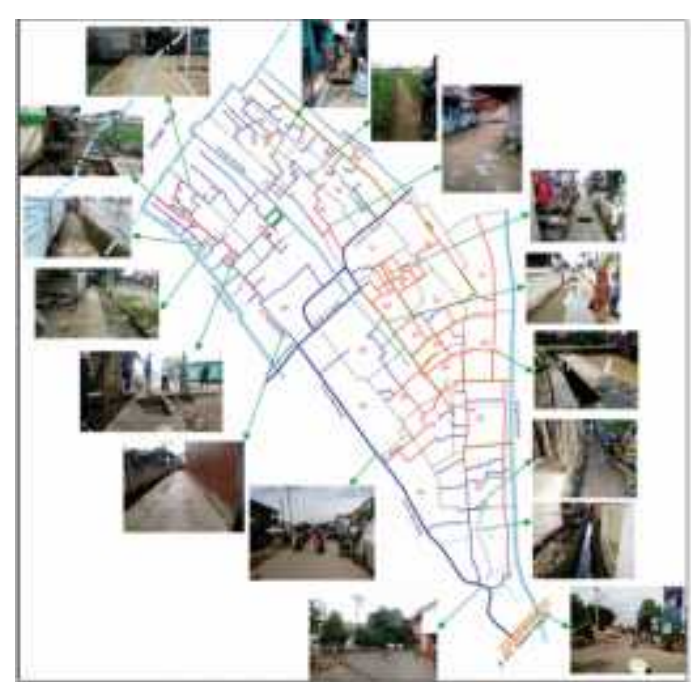

Gambar 8. Kondisi Eksisting di seputaran lokasi utama

\section{Rencana Penanganan dan RAB Pembangunan Jalan Lingkungan}

Sistem jaringan jalan wilayah perencanaan (Kel. 3-4 Ulu) disusun dengan mengacu pada RTRW Kota Palembang dan dengan memperhatikan keterhubungan antar kawasan dan/atau dalam kawasan yang dalam penjabarannya adalah keterhubungan antar pusatpusat kegiatan sesuai dengan hirarki.

Rencana pengembangan jaringan jalan di kawasan perencanaan didasarkan pada pertimbangan;

- Penataan hierarki jalan yang menerus meliputi jalan arteri, kolektor dan jalan lokal sesuai dengan karakteristik hirarki jalan yang berlaku

- Memelihara fungsi jaringan jalan primer dengan membatasi jalan akses lokal, menghilangkan gangguan pada badan jalan dan pengendalian pemanfaatan ruang pada jalan tersebut.

- Meningkatkan fungsi jaringan jalan yang ada dengan cara pelebaran jalan, pembatasan parkir pada jalan tersebut, pembatasan penggunaan badan jalan untuk keperluan yang lain, perbaikan perkerasan, dan pengaturan lalu lintas angkutan umum

- Meningkatkan akses jalan pada kawasan perumahan padat dengan struktur pergerakan yang lebih tertata.

Rencana sistem sirkulasi dikembangkan dengan dasar-dasar pertimbangan sebagai berikut:
- Kedekatan dengan akses jaringan jalan yang telah ada;

- Struktur ruang dan arahan zonasi/ blok kawasan;

Jejalur berupa jaringan jalan adalah penghubung antara komponen kegiatan dari daerah satu dengan daerah yang lain. Disamping itu jaringan jalan juga akan mempengaruhi struktur tata ruang suatu daerah.

Rencana jaringan jalan merupakan penelaahan pola jaringan jalan eksisting terhadap kecenderungan penduduk dari kawasan lain. Dari hasil pengamatan dapat ditentukan kelayakan pola jaringan yang telah ada, penggal-penggal jalan penunjang pola jaringan jalan, serta arahan bagi bentukan jalan yang baru, pola jaringan yang ada pada Kelurahan 3-4 Ulu adalah berbentuk linier.

Skenario penanganan kegiatan jalan lingkungan meliputi :

- Pembangunan jalan rabat beton dengan syarat lebar minimal $\geq 1,50 \mathrm{~m}$, dan berfungsi sebagai jalan penghubung antar lingkungan

- Pembangunan jalan beton bertiang dilaksanakan dilokasi dari tinggian dari muka tanah $0,60 \mathrm{~m} \mathrm{~s} / \mathrm{d} 0,90 \mathrm{~m}$ terhadap elevasi jalan yang sudah ada

- Rehab. jalan rabat beton dan jalan beton bertiang dengan syarat lebar jalan yg ada minimal $\geq 1,50 \mathrm{~m}$, atau pelebaran jalan menjadi $\geq 1,50 \mathrm{~m}$.

Kondisi eksisting menunjukan bahwa ruas-ruas jalan di wilayah perencanaan telah terbagi berdasarkan klasifikasi sistem hirarki dan fungsi jalan. Penentuan hirarki dan fungsi jalan ini dimaksudkan untuk menghindari terjadinya pencampuran pergerakan regional dan lokal wilayah perencanaan, yaitu :

$>$ Jl. KH. Wahid Hasyim dikategorikan sebagai jalan kolektor primer (jalur trayek umum dari Terminal Karang Jaya s/d ke Terminal Sako

Jl. K.H.A. Azhari dikategorikan sebagai jalan kolektor sekunder (jalur trayek angkot)

$>$ Jl. KH. Moh. Asyik dan Jl. H. Faqih Usman di kategorikan sebagai jalan lokal sekunder yaitu jalan yang terhubung dengan kegiatan skala lingkungan di wilayah perencanaan

\section{Rencana Penanganan/ Peningkatan Jalan Lingkungan}

Rencana penanganan jalan lingkungan di kawasan prioritas meliputi : 
1. Bongkaran jalan beton bertiang yang sudah rusak berat dan jalan struktur kayu dan pembuatan kembali jalan beton bertiang, dengan lebar $\geq 1,50 \mathrm{~m}$

2. Pembuatan jalan beton bertiang baru sebagai akses jalan penghubung, dengan lebar $\geq 1,50$ $\mathrm{m}$

3. Rehab. dan pelebaran jalan beton bertiang dari lebar $1,20 \mathrm{~m}$ menjadi $1,50 \mathrm{~m}$

4. Pembuatan jalan rabat beton baru sebagai akses jalan penghubung, dengan lebar $\geq 1,50$ $\mathrm{m}$

5. Rehab. dan pelebaran jalan rabat beton dari lebar $1,20 \mathrm{~m}$ menjadi $1,50 \mathrm{~m}$

6. Pemasangan paving block jalan dengan lebar $\geq 1,50 \mathrm{~m}$

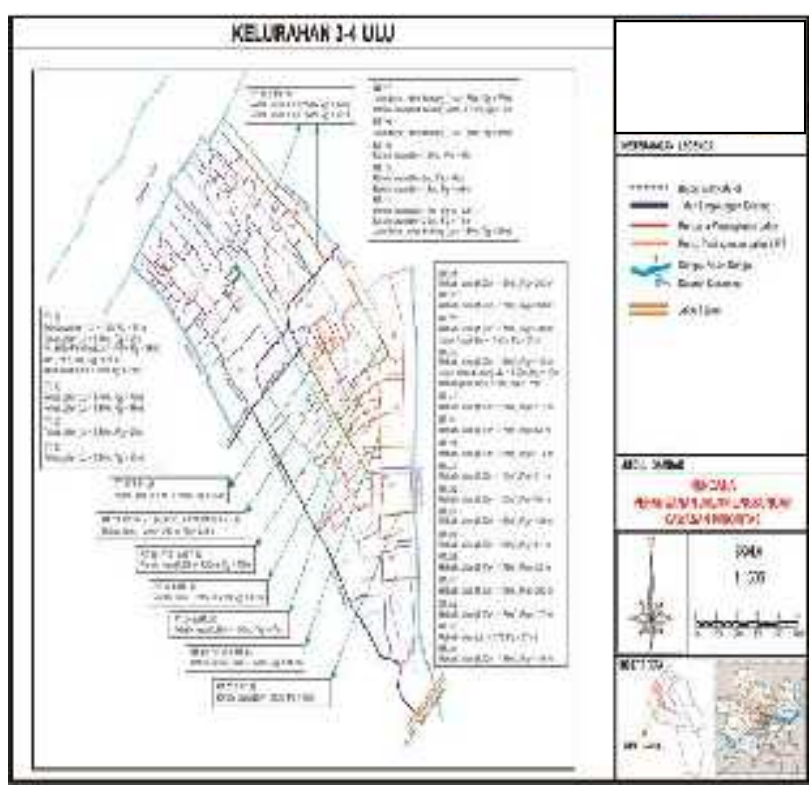

Gambar.9. Peta Rencana Peningkatan Jalan Kawasan Prioritas

Dari peta tematik di atas dapat dilihat kebutuhan infrastruktur jalan di kawasan 3-4 Ulu.

\section{E. DED Pembangunan Jalan Infrastruktur di Kel 3-4 Ulu}

\section{Pembuatan Jalan Rabat Beton}

Berdasarkan hasil survey dan wawancara dengan stake holder pihak kelurahan, maka dapat dibuat DED dan Rencana Anggaran Biaya Penanganan infrastruktur jalan. DED secara detail dapat dilihat pada gambar di bawah ini.

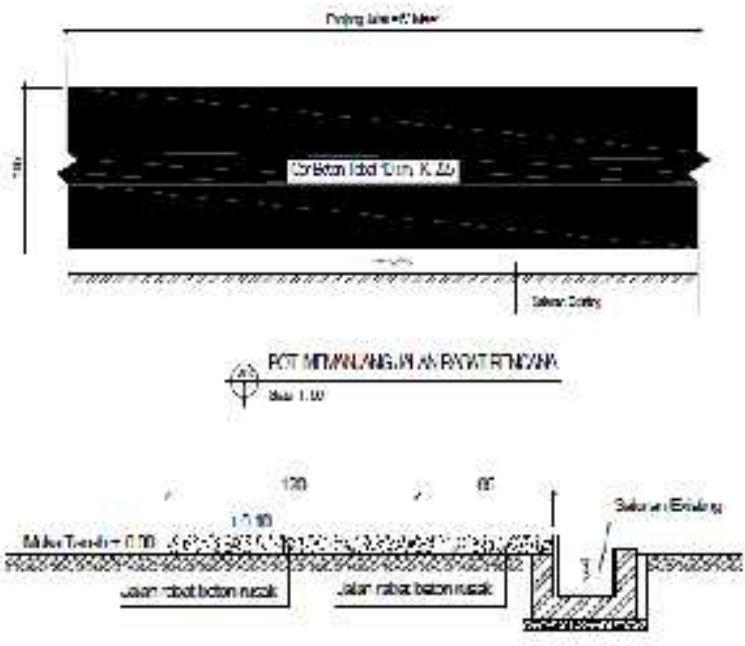

Th. Jalantratial exsiano

atas 1:06

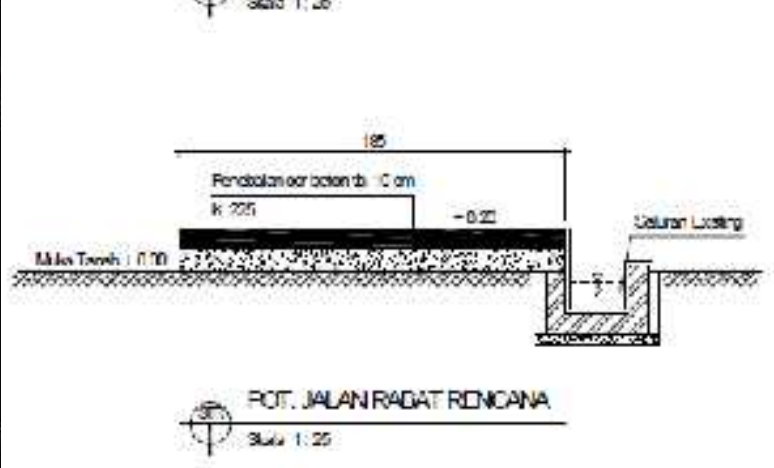

Gambar 10 DED Infrastruktur Jalan

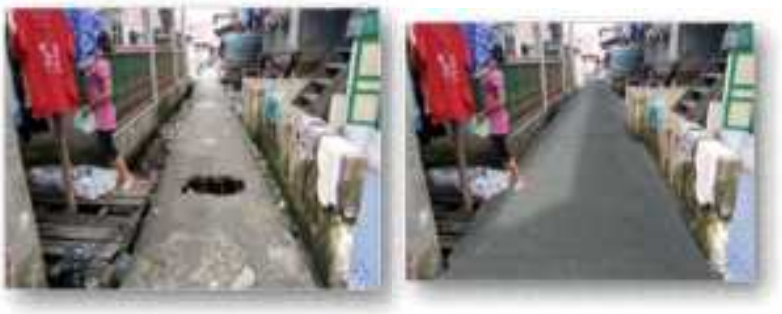

Gambar.11 Kondisi Eksisting dan Kondisi Rencana Infrastruktur Jalan Rabat Beton 
Tabel 1. RAB Infrastruktur Jalan di Kawasan Kelurahan 3-4 Ulu

\begin{tabular}{|c|c|c|c|c|c|c|}
\hline No. & URAIAN PEKERJAAN & LOKASI & VOLUME & SAT. & $\begin{array}{c}\text { HARGA } \\
\text { SATUAN } \\
\text { (Rp.) }\end{array}$ & $\begin{array}{c}\text { JUMLAH } \\
\text { HARGA } \\
\text { (Rp.) }\end{array}$ \\
\hline \multirow[t]{2}{*}{ I. } & PEK. REHAB. / JALAN RABAT BETON (Lbr. 1,85m; Pjg. 63) & RT. 12 & & & & \\
\hline & Pek. Beskisting Samping & & 25,20 & M2 & $131.470,00$ & $3.313 .044,00$ \\
\hline \multirow[t]{2}{*}{2} & Pek. Pengecoran Lantai Tbl $10 \mathrm{~cm}$ Ad. $1: 23$ & & 11,66 & M3 & $1.020 .636,46$ & $11.895 .517,95$ \\
\hline & & & & & Jumlah & \begin{tabular}{|l|l|}
$15.208 .561,95$ \\
\end{tabular} \\
\hline \multirow{2}{*}{ II. } & PEK. REHAB. /JALAN RABAT BETON (Lbr. 2,40m; Pjg. 42m) & RT. 12 & & & & \\
\hline & Pek. Beskiting Samping & & 16,80 & M2 & $131.470,00$ & $2.208 .696,00$ \\
\hline & Pek. Pengecoran Lantai TbL $10 \mathrm{~cm}$ Ad. $12: 3$ & & 10,08 & M3 & $1.020 .636,46$ & $10.288 .015,52$ \\
\hline & & & & & Jumlah & \begin{tabular}{|l|l|}
$12.496 .711,52$ \\
\end{tabular} \\
\hline III. & PEK. REHAB. /JALAN RABAT BETON (Lbr. 2,40m; ; Pj. 46m) & RT. 09 & & & & \\
\hline 1 & \begin{tabular}{|l} 
Pek. Beskisting Samping \\
\end{tabular} & & 18,40 & M2 & $131.470,00$ & $2.419 .048,00$ \\
\hline 2 & Pek. Pengecoran Lantai TbL $10 \mathrm{~cm} \mathrm{Ad.12:3}$ & & 11,04 & M3 & $1.020 .636,46$ & $11.267 .826,52$ \\
\hline & & & & & Jumlah & \begin{tabular}{|l|}
$13.686 .874,52$ \\
\end{tabular} \\
\hline IV. & PEK. JALAN RABAT BETON (Lbr. 1,50m; Pjg. 21m) & RT. 12 & & & & \\
\hline 1 & Pek. Beskisting Samping & & 8,40 & $\mathrm{M} 2$ & $131.470,00$ & $1.104 .348,00$ \\
\hline 2 & Pek. Pengecoran Lantai Tbl $10 \mathrm{~cm} \mathrm{Ad.} \mathrm{1:23:3}$ & & 3,15 & M3 & $1.020 .636,46$ & $3.215 .004,85$ \\
\hline & & & & & Jumlah & $4.319 .352,85$ \\
\hline v. & PEK. REHAB. / JALAN RABAT BETON (Lbr. 3,00m - 2,60m ; P. & RT. 08 & & & & \\
\hline 1 & Pek. Bobokan beton jalan untuk sal. Draianase & & 2,20 & M3 & $1.066 .720,00$ & $2.346 .784,00$ \\
\hline 2 & Pek. Beskisting Samping & & 22,00 & M2 & $131.470,00$ & $2.892 .340,00$ \\
\hline 3 & Pek. Pengecoran Lantai Tbl $10 \mathrm{~cm}$ Ad. $1: 23$ & & 14,30 & M3 & $1.020 .636,46$ & \begin{tabular}{|l|l|}
$14.595 .101,38$ \\
\end{tabular} \\
\hline & & & & & Jumlah & \begin{tabular}{|l|l|}
$19.834 .225,38$ \\
\end{tabular} \\
\hline VI. & $\begin{array}{l}\text { PEK. REHAB. JALAN RABAT BETON (Lebar. 1,50m) } \\
\end{array}$ & RT. $10,17,19$ & & & & \\
\hline & Panjang $(22 m+261 m+23 m+192 m+57 m+95 m)=650$ & RT. $13,14,22$ & & & & \\
\hline 1 & Pek. Beskisting Samping & RT. $23 \& 33$ & 260,00 & M2 & $131.470,00$ & \begin{tabular}{|l|l|}
$34.182 .200,00$ \\
\end{tabular} \\
\hline 2 & Pek. Pengecoran Lantai Tbl $10 \mathrm{~cm} \mathrm{Ad.} 1: 23$ & & 97,50 & M3 & $1.020 .636,46$ & \begin{tabular}{|l|l|l|l|}
$99.544,88$ \\
\end{tabular} \\
\hline & & & & & Jumlah & $133.694 .254,88$ \\
\hline VII. & PEK. REHAB. JALAN RABAT BETON (Lebar. 1,60m) & RT. 16 \& 23 & & & & \\
\hline & Panjang $(49 \mathrm{~m}+128 \mathrm{~m})=177 \mathrm{M}$ & & & & & \\
\hline 1 & Pek. Beskisting Samping & & 70,80 & M2 & $131.470,00$ & $9,308.076,00$ \\
\hline 2 & Pek. Pengecoran Lantai TbL $10 \mathrm{~cm} \mathrm{Ad.12:3}$ & & 28,32 & M3 & $1.020 .636,46$ & \begin{tabular}{|l|}
$28.904 .424,56$ \\
\end{tabular} \\
\hline & & & & & Jumlah & \begin{tabular}{|l|}
$38.212 .500,56$ \\
\end{tabular} \\
\hline VIII & PEK. REHAB. JALAN RABAT BETON (Lbr. 2,00m ; Pjg. 55m) & RT. 13 & & & & \\
\hline 1 & Pek. Beskisting Samping & & 22,00 & M2 & $131.470,00$ & $2.892 .340,00$ \\
\hline 2 & Pek. Pengecoran Lantai Tbl $10 \mathrm{~cm}$ Ad. $12: 3$ & & 11,00 & M3 & $1.020 .636,46$ & \begin{tabular}{|l|l|}
$11.227 .001,06$ \\
\end{tabular} \\
\hline & & & & & Jumlah & \begin{tabular}{|l|}
$14.119 .341,06$ \\
\end{tabular} \\
\hline & & & & & & \\
\hline IX. & PEK. PELEBARAN JALAN RABAT BETON (Lbr. 1,20m - 1,50 & RT. 13, RT. 20 & & & & \\
\hline & (Panjang $=34 \mathrm{~m}+243 \mathrm{~m}+260 \mathrm{~m}+248 \mathrm{~m}+143 \mathrm{~m}+312 \mathrm{~m})=1240 \mathrm{~m}$ & \begin{tabular}{|l|} 
RT. 21, RT. 22 \\
\end{tabular} & & & & \\
\hline & Pek. Galian Tanah & \begin{tabular}{|l|l} 
RT. 23, RT. 47 \\
\end{tabular} & 37,20 & M3 & $60.000,00$ & $2.232 .000,00$ \\
\hline 2 & Pek. Unugan Pasir & & 18,60 & M3 & $115.200,00$ & $2.142 .720,00$ \\
\hline & Pek. Ris Batubata & & 49,60 & M2 & $80.353,07$ & $3.985 .512,27$ \\
\hline 4 & Pek. Plesteran Ris. Luar & & 496,00 & M2 & $49.070,40$ & \begin{tabular}{|l|l|}
$24.338 .918,40$ \\
\end{tabular} \\
\hline 5 & Pek. Pengecoran Lantai Tbl. $10 \mathrm{~cm} \mathrm{Ad.12:3}$ & & 186,00 & M3 & $1.020 .636,46$ & $1899.838 .381,62$ \\
\hline & & & & & Jumlah & $222.537 .532,29$ \\
\hline & & & & & & \\
\hline $\mathrm{x}$ & PEK. PELEBARAN JALAN RABAT BETON (Lbr. 1,20m - 1,50 & RT. 51, RT. 28 & & & & \\
\hline & (Panjang $=84 m+174 m+51 m+76 m+138 m+61 m)=584 m$ & RT. 27, RT. 52 & & & & \\
\hline 1 & Pek. Galian Tanah & \begin{tabular}{|l|} 
RT. 24, RT. 26 \\
\end{tabular} & 17,52 & M3 & $60.000,00$ & $1.051 .200,00$ \\
\hline 2 & Pek. Unugan Pasiri & & 8,76 & M3 & $115.200,00$ & $1.009 .152,00$ \\
\hline 3 & Pek. Ris Batubata & & 23,36 & M2 & $80.353,07$ & $1.877 .047,72$ \\
\hline 4 & Pek. Plesteran Ris. Luar & & 233,60 & M2 & $49.070,40$ & $11.462 .845,44$ \\
\hline & Pek. Pengecoran Lantai Tbl $10 \mathrm{~cm} \mathrm{Ad.} 1: 23$ & & 87,60 & M3 & $1.020 .636,46$ & \begin{tabular}{|l|l|}
$89.407 .753,92$ \\
\end{tabular} \\
\hline & & & & & Jumlah & \begin{tabular}{|l|l|}
$104.807 .999,08$ \\
\end{tabular} \\
\hline & & & & & & \\
\hline XI. & PEK. PELEBARAN JALAN RABAT BETON (Lbr. 1,20m - 1,50 & RT. 25, RT. 31 & & & & \\
\hline & (Panjang $=48 m+202 m+173 m+136 m)=559 m$ & RT. 32, RT. 34 & & & & \\
\hline 1 & Pek. Galian Tanah & & 16,77 & M3 & $60.000,00$ & $1.006 .200,00$ \\
\hline & Pek. Unigan Pasir & & 8,39 & M3 & $115.200,00$ & $965.952,00$ \\
\hline 3 & Pek. Ris Batubata & & 22,36 & M2 & $80.353,07$ & $1.796 .694,65$ \\
\hline & Pek. Plesteran Ris. Luar & & 223,60 & M2 & $49.070,40$ & $10.972 .141,44$ \\
\hline 5 & Pek. Pengecoran Lantai Tbl $10 \mathrm{~cm}$ Ad. $1: 233$ & & 83,85 & M3 & $1.020 .636,46$ & $85.580 .367,20$ \\
\hline & & & & & Jumlah & $100.321 .355,28$ \\
\hline & & & & & & \\
\hline XII. & PEK. PELEBARAN JALAN RABAT BETON (Lbr. 1,20m - 1,50 & RT. $24 \&$ RT. 47 & & & & \\
\hline & (Panjang $=122 \mathrm{~m}+239 \mathrm{~m}+156 \mathrm{~m}+132 \mathrm{~m}+47 \mathrm{~m}+167 \mathrm{~m})=863 \mathrm{~m}$ & RT. 26, 28, 27 & & & & \\
\hline 1 & Pek. Galian Tanah & $52,24,25 \& 26$ & 25,89 & M3 & $60.000,00$ & $1.553 .400,00$ \\
\hline 2 & Pek. Unigan Pasir & RT. $20,21 \& 22$ & 12,95 & M3 & $115.200,00$ & $1.491 .264,00$ \\
\hline 3 & Pek. Ris Batubata & RT. $27 \&$ RT. 52 & 34,52 & $\mathrm{M} 2$ & $80.353,07$ & $2.773 .787,98$ \\
\hline 4 & Pek. Plesteran Ris. Luar & RT. $22,23 \& 24$ & 345,20 & $\mathrm{M} 2$ & $49.070,40$ & $16.939 .102,08$ \\
\hline 5 & Pek. Pengecoran Lantai Tbl $10 \mathrm{~cm} \mathrm{Ad.} 12: 3$ & & 129,45 & M3 & $1.020 .636,46$ & \begin{tabular}{|l|l|}
$132.121 .389,79$ \\
\end{tabular} \\
\hline & & & & & Jumlah & \begin{tabular}{|l|l|}
$154.878 .943,84$ \\
\end{tabular} \\
\hline XIII. & PEK. REHAB. JALAN RABAT BETON (Lebar. 2,50m) & RT. 17,19 & & & & \\
\hline & Panjang $(37 \mathrm{~m}+19 \mathrm{~m})=56 \mathrm{M}$ & \& RT. 14 & & & & \\
\hline 1 & Pek. Beskiting Samping & & 22,40 & M2 & $131.470,00$ & $2.944 .928,00$ \\
\hline & Pek. Pengecoran Lantai Tbl $10 \mathrm{~cm} \mathrm{Ad.12:3}$ & & 14,00 & M3 & $1.020 .636,46$ & \begin{tabular}{|l|l|}
$14.288 .910,44$ \\
\end{tabular} \\
\hline & & & & & Jumlah & \begin{tabular}{|l|l|}
$17.233 .838,44$ \\
\end{tabular} \\
\hline XIV. & \begin{tabular}{|l} 
PEK. REHAB. JALAN RABAT BETON (Lebar. 2,70m ; Panjang \\
\end{tabular} & RT. 33 & & & & \\
\hline & Pek. Beskiting Samping & & 22,80 & M2 & $131.470,00$ & $2.997 .516,00$ \\
\hline 2 & Pek. Pengecoran Lantai Tbl $10 \mathrm{~cm} \mathrm{Ad.} 12: 23$ & & 15,39 & M3 & $1.020 .636,46$ & $15.707 .595,12$ \\
\hline & & & & & Jumlah & \begin{tabular}{|l|}
$18.705 .111,12$ \\
\end{tabular} \\
\hline $\mathrm{xv}$. & \begin{tabular}{|l} 
PEK. REHAB. JALAN RABAT BETON (Lebar. 1,80 ; Panjang \\
\end{tabular} & RT. 09 & & & & \\
\hline 1 & Pek. Beskisting Samping & & 36,40 & M2 & $131.470,00$ & $4.785 .508,00$ \\
\hline 2 & Pek. Pengecoran Lantai Tbl. $10 \mathrm{~cm}$ Ad. $12: 3$ & & 16,38 & M3 & $1.020 .636,46$ & \begin{tabular}{|l|}
$16.718 .025,22$ \\
\end{tabular} \\
\hline & & & & & Jumlah & $21.503 .533,22$ \\
\hline & & & & & & \\
\hline
\end{tabular}

\section{Pembuatan Jalan Rabat Beton Bertiang (Jalan titian) \\ Berdasarkan hasil survey dan wawancara} dengan stake holder pihak kelurahan, maka dapat dibuat DED dan Rencana Anggaran Biaya Penanganan infrastruktur jalan. DED secara detail dapat dilihat pada gambar di bawah ini.
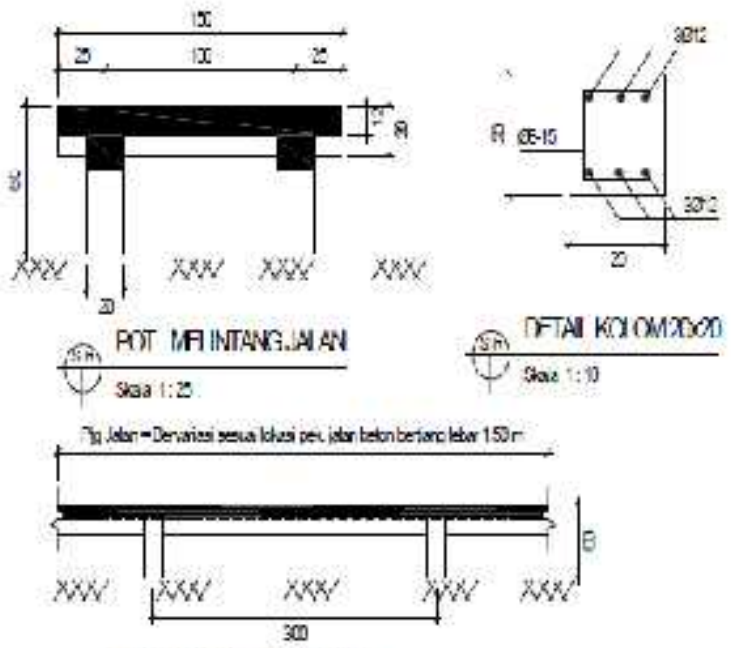

POT. RERWWKGNW

W' satis

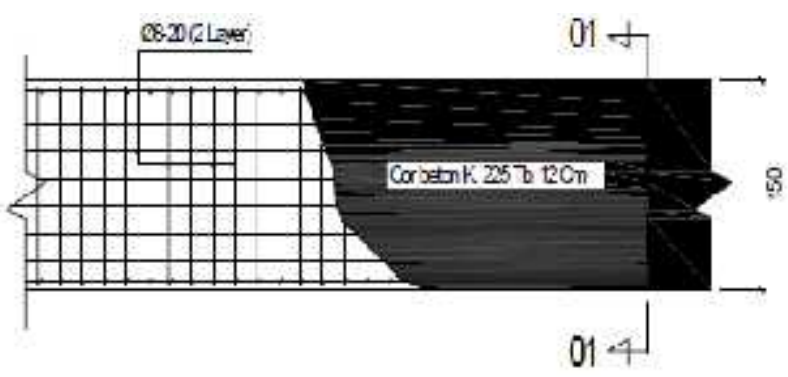

DETNLPEMEESINPLTLWTN

$\psi_{\text {Ska } 1: 50}$

Gambar.12 DED Jalan Titian 
Tabel 1. Total RAB pembangunan Jaringan Infrastruktur Jalan Lingkungan

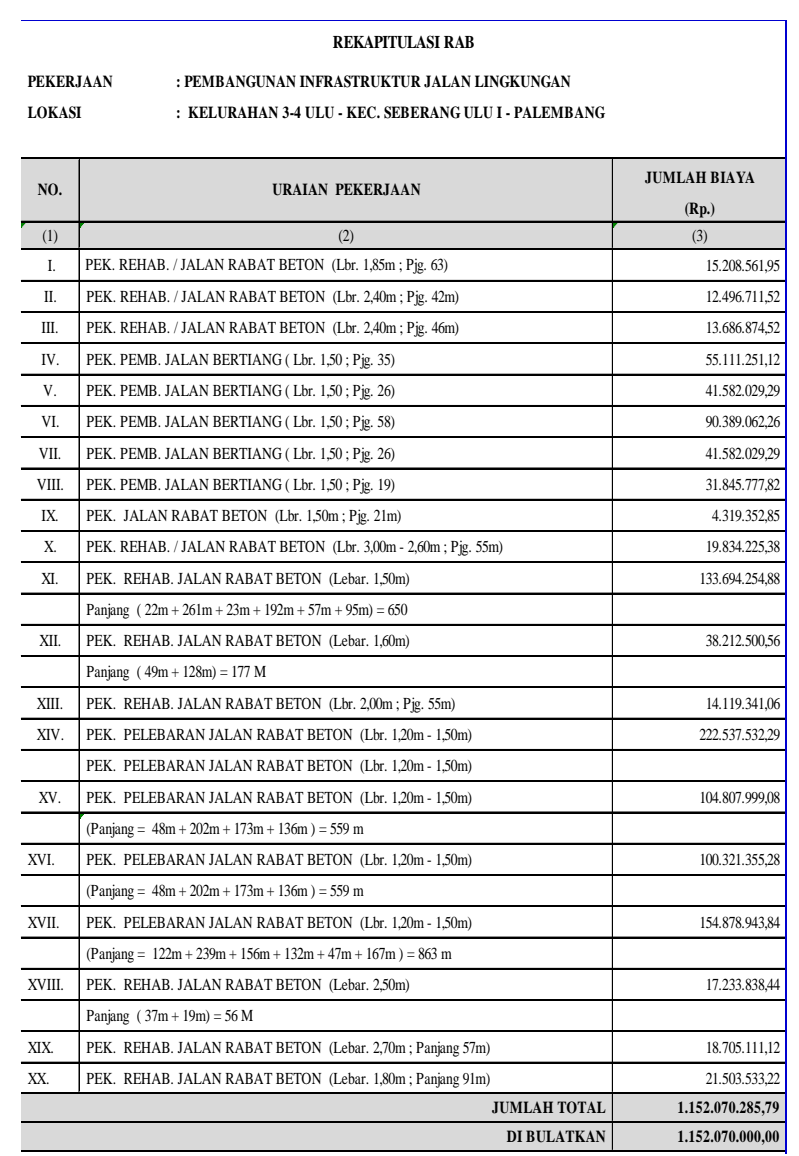

Dari hasil perhitungan di dapatkan total Rencana Anggaran Biaya yang dibutuhkan untuk pembangunan sarana infrastruktur jalan di kelurahan 3-4 Ulu adalah Rp. 1.152.070.000,-.

\section{KESIMPULAN}

1. Kondisi eksisting infrastruktur jalan lingkungan di Kelurahan 3-4 Ulu ini sangat membutuhkan penanganan khusus, karena kawasan 3-4 ulu ini merupakan kawasan yang dekat dengan kota, namun memiliki tingkat kekumuhan yang cukup tinggi, dan salah satu halnya dapat dilihat dari infrastruktur jalan yang masih membutuhkan banyak penanganan.

2. Perencanaan pembangunan infrastruktur jalan lingkungan yang terintegrasi dapat dilakukan dengan scenario sebagai berikut :

a) Bongkaran jalan beton bertiang yang sudah rusak berat dan jalan struktur kayu dan pembuatan kembali jalan beton bertiang, dengan lebar $\geq 1,50 \mathrm{~m}$ b) Pembuatan jalan beton bertiang baru sebagai akses jalan penghubung, dengan lebar $\geq 1,50$ $\mathrm{m}$

c) Rehab. dan pelebaran jalan beton bertiang dari lebar 1,20 m menjadi $1,50 \mathrm{~m}$

d) Pembuatan jalan rabat beton baru sebagai akses jalan penghubung, dengan lebar $\geq 1,50$ $\mathrm{m}$

e) Rehab. dan pelebaran jalan rabat beton dari lebar $1,20 \mathrm{~m}$ menjadi $1,50 \mathrm{~m}$

Pembangunan dilakukan sesuai dengan kebutuhan di masing - masing RT.

3. Biaya yang dibutuhkan untuk pembangunan infrastruktur jalan lingkungan di kelurahan 34 Ulu adalah Rp. Rp. 1.152.070.000,-.

\section{DAFTAR PUSTAKA}

Buku

Soehardi Sigit,1999, Pengantar Metodologi Penelitian, Jogyakarta

Soeharto, Iman, 1997, Manajemen Proyek, Penerbit Erlangga, Jakarta

Sugiyono. 2008, Metode Penelitian Kuantitatif

Kualitatif dan $R \& D$. Bandung:

Alfabeta.

Internet

http://www.fhwa.dot.gov/environment/flex/ch03. htm\%7CFunctional Classification

http://www.cher.ubc.ca/UBCBAQS/SSL05-014TRAFFIC.pdf |Road Classification

\section{Schemes}

http://hubdat.web.id/uu/54-uu-no/download Undang-undang Republik Indonesia no 38 tahun 2004 tentang jalan

Undang-Undang Republik Indonesia No 22

Tahun 2009 tentang Lalu Lintas dan

Angkutan jalan

Undang-Undang Republik Indonesia No 14 Tahun 1992 tentang Lalu Lintas dan Angkutan jalan

Sunaryo Joyopuspito, Jalan Raya I dan II, Kuliah dan Kliping, Universitas Trisakti Jakarta, 1989

https://www.soilindo.com/jenis-pengerasanjalan-lingkungan-populer/ 